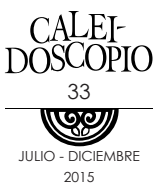

\title{
El desarrollo de la educación media superior. Una perspectiva histórica ${ }^{1}$
}

FELIPE MARTÍNEZ RIZO²

\section{RESUMEN}

El texto describe el desarrollo de los sistemas educativos que comienza con el nacimiento de las universidades en los siglos XII y XIII y continúa hacia el XVI con el surgimiento de los liceos, antepasados de la educación media superior. Se analiza luego la expansión de los sistemas educativos, primero según el "modelo dual" que separa tempranamente a los niños que se espera lleguen a la universidad de los que se incorporan pronto al mercado de trabajo. Con el antecedente temprano de los Estados Unidos, a mediados del siglo xx se extiende el "modelo comprensivo", en que todos los jóvenes estudian en escuelas similares hasta el final de la media superior. Se analiza la dificultad que se ha encontrado en todos los países para universalizar este tipo educativo y se sacan conclusiones para el sistema educativo mexicano.

Palabras clave: sistemas educativos, educación media superior, educación universal, historia.

1 Este artículo se deriva de un capítulo del autor mucho más extenso previamente publicado, y aprovecha algunos elementos del mismo. El capítulo en cuestión se encuentra en: Martínez Rizo, F. (2012). El futuro de la educación media superior. En Martínez Espinoza, M. Á. (Coord.). La educación media superior en México. Balance y perspectivas, pp. 220-287. México, FCE-SEP. ISBN 978-607-16-0851-2.

2 Licenciado en Ciencias Sociales por la Universidad de Lovaina. Pertenece al Sistema Nacional de Investigadores y a la Academia Mexicana de Ciencias. Recibió el Premio AnuIES, la Medalla de la Facultad de Filosofía y Educación y el Doctorado Honoris Causa de la Universidad de Valencia. felipemartinez.rizo@gmail.com. 


\section{ABSTRACT}

This paper describes the development of education systems, beginning with the birth of universities in the twelfth and thirteenth centuries, and in the XVI continues with the emergence of lyceums, forefathers of high schools. The expansion of education systems is analyzed, first by the "dual model", which separates early children who are expected to reach college and those who will be integrated soon into the labor market; then with the "comprehensive model", first in the United States, and since mid-twentieth century in other countries. In this model all young people study in similar schools until the end of high school. Finally, it is analyzed the difficulty found in all countries to universalize upper secondary education, and conclusions are drawn for Mexican education.

Key words: education systems, upper secondary education, universal education, history.

\section{INTRODUCCIÓN}

Los sistemas educativos que hoy existen en todos los países suelen distinguir tres etapas: educación primaria, secundaria y terciaria, o bien, básica, media y superior.

La enseñanza primaria o elemental tiene siempre carácter de obligatoria y se concibe como la que debe proporcionar a todo futuro ciudadano el bagaje mínimo para vivir en la sociedad, por lo que también se le designa con el término de básica. El propósito de la educación superior ha tenido siempre que ver con la preparación de personal calificado para desempeñar tareas especializadas de naturaleza profesional, por lo que se ha considerado también como reservado a una minoría o, al menos, no a la totalidad de la población. Entre esos dos niveles, la definición de la enseñanza secundaria o media ha sido menos clara, entre una prolongación de la primaria, con sus rasgos de educación básica, y una preparación para la enseñanza superior, con carácter propedéutico.

Esta configuración en tres niveles de los sistemas educativos es el resultado de un proceso secular sobre el que suele haber ideas inexactas. Parece lógico pensar que en el primer momento habrían aparecido las escuelas elementales, seguidas por las de tipo medio y, por último, las de nivel superior, pero en realidad ocurrió lo contrario. 
Randall Collins (1990) muestra que el desarrollo de las instituciones educativas modernas tuvo lugar de arriba hacia abajo, y no al revés. De los siglos XII y XIII datan las primeras universidades; los primeros liceos y planteles similares, que hoy podrían considerarse de enseñanza media, surgieron a fines del siglo XV y principios del XVI; y las escuelas de primeras letras, con los antecedentes remotos mencionados, comenzaron a tomar una forma reconocible para la mirada actual hasta los siglos XVIII y XIX O, a lo más, a fines del XVII, como ocurrió en Prusia.

En las sociedades primitivas, la familia extendida, el clan o la tribu cumplían todas las funciones que en formaciones sociales más complejas se asignan a instituciones especializadas. La socialización primaria y la secundaria, en particular, además de la interiorización de los roles fundamentales de varón/mujer, padre/madre, hijo/hija, abuelo, tío, nieto, sobrino y otros, bastaban para asegurar que hacia los 15 años de edad, los jóvenes hubieran aprendido todo lo que necesitaban para defenderse en la vida y accedieran al estatus de adulto sancionado por diversos ritos de paso.

Al volverse más complejos los grupos humanos, la aparición de las primeras formas de Estado se vio acompañada por el surgimiento de instituciones educativas dirigidas inicialmente no a niños sino a jóvenes, para prepararlos para funciones adultas especializadas como la milicia, el sacerdocio, la escritura y otras actividades cultas como la astronomía o la filosofía. La educación de los efebos era actividad de adultos, como los estudios que se impartían en la Academia de Platón, el Liceo de Aristóteles o la escuela de retórica de Isócrates.

\section{LAS PRIMERAS INSTITUCIONES EDUCATIVAS: LAS UNIVERSIDADES}

Los estudiantes de las actuales instituciones de educación superior, aun de nuevo ingreso a licenciatura o técnico superior, tienen 18 años o más, por lo que legalmente son adultos. La edad de ingreso a la universidad medieval era menor, pero los estudiantes también eran considerados adultos, como lo muestra el que tanto ellos como los maestros de los studia generalia podían agremiarse en corporaciones: universitas magistrorum aut scholarium.

Esas universidades medievales fueron las primeras instituciones educativas. En la baja Edad Media no había otras con ese carácter. 
La enseñanza de primeras letras se limitaba a los hijos de familias acomodadas y tenía lugar en el hogar, a cargo de instructores privados de bajo estatus, como los instructores, esclavos o no, que los griegos llamaban pedagogos y los romanos grammatici. Conviene añadir que la enseñanza de una lengua se refería al latín y no a la lengua vernácula, que no necesitaba de escuela para aprenderse. Desde la antigüedad, algunos maestros ofrecían enseñanza a pocos alumnos de familias diferentes. Quintiliano discutía ya las ventajas y desventajas de la enseñanza en el hogar o en un grupo en casa de un grammaticus (cfr. Johannesson, 1994).

En una u otra forma, esa enseñanza elemental estaba restringida a una pequeña elite y se reducía al aprendizaje de la lectura, al que se añadían, como elementos menos esenciales, el manejo de la escritura y los rudimentos de la aritmética. Los conocimientos más amplios de gramática, retórica y dialéctica (trivium), así como de aritmética, geometría, astronomía y música (quadrivium), eran el contenido de la facultad de artes de las universidades medievales en las que adultos que ya sabían leer y escribir en latín se preparaban para acceder a facultades especializadas de teología, derecho o medicina. Se daba por sentado que la mayoría de la población no necesitaba saber leer y escribir, pues se dedicaría a actividades que no lo requerían, como la agricultura (cfr. Gaulupeau, 1992: 26).

A lo largo del siglo XII, y con más fuerza en el xIII y el xIV, a partir de escuelas catedralicias y otros orígenes modestos surgieron las universidades de París, Boloña, Montpellier, Padua, Orleans y Oxford, seguidas por Cambridge, Aviñón, Siena, Heidelberg, Colonia, Praga, Cracovia, Palencia, Salamanca y muchas otras, con diversa fortuna. Hacia 1300 funcionaban en Europa entre 15 y 20 universidades, y en 1500 el número llegaba a 70 (Cobban, 1994: 1246-1248).

\section{El surgimiento de los liceos}

Las características de las primeras universidades correspondían a su entorno: una sociedad feudal, integrada por señores y siervos que se dedicaban a labores del campo, un estrato de artesanos y un poderoso sector eclesiástico estrechamente ligado a la nobleza.

En ese contexto era funcional una educación con fuerte componente filosófico y teológico que se impartía en latín, lenguaje necesario para el ejercicio de cualquier actividad letrada de religiosos y 
laicos, del derecho canónico y el derecho civil, y también para la medicina o la arquitectura, ya que la lengua de comunicación entre las personas cultas de cualquier nación era el latín.

La sociedad feudal, y con ella las universidades, entraron en crisis desde mediados del siglo xIV con la llegada de la primera oleada de la plaga: la peste negra que redujo la población de Europa de unos 65 millones de habitantes que había alcanzado en 1340, a menos de 40 millones en 1420 (cfr. Chaunu, 1982: 116).

La recuperación de la población, desde la segunda mitad del siglo XV y a lo largo del XVI, fue acompañada por otros fenómenos culturales y económicos, en particular del Renacimiento, la Reforma protestante y la Contrarreforma católica, y también del paulatino surgimiento de la burguesía como nueva clase social que sustituiría a la nobleza como clase dominante con las revoluciones políticas del XVIII y el XIX, y con la Revolución Industrial que transformó los viejos modos de producción. Harold Perkin afirma:

Con unas cuantas excepciones en Escocia, los Países Bajos y Alemania, la mayoría de las universidades europeas del siglo xvill estaban moribundas, con ociosos profesores que enseñaban lánguidamente un currículo medieval irrelevante para la vida moderna, despreciados por los intelectuales de la ilustración. (Perkin, 1997: 15)

En este contexto comenzó el surgimiento de nuevas instituciones educativas. Desde el siglo XV, ante la creciente demanda de una educación que respondiera mejor a las necesidades de los hijos de artesanos prósperos y burgueses, surgió otro tipo de plantel que está en el origen de nuestra educación media superior: los colegios o liceos, que a lo largo del XVI y el XVII rivalizaron con las ya viejas universidades y ocuparon su lugar para la formación de las elites laicas y las profesiones no clericales.

Esta tendencia hacia nuevas formas de educación continuaría en los siglos XVIII y XIX con la aparición de escuelas de agronomía, de minas, de caminos y puentes y de ingenieros militares, precursoras de tecnológicos y politécnicos, para preparar a los especialistas que demandaba el desarrollo económico producido por la revolución industrial.

También desde el siglo Xvil surgieron academias y sociedades científicas que reunían a estudiosos de la naturaleza y eruditos. En el XIX también algunas universidades adoptaron formas de organización moderna, como la que Guillermo de Humboldt fundó en Berlín, paradigma de las universidades de investigación actuales. 
Por su parte, las escuelas elementales, muy escasas en el siglo XV, en las siguientes centurias crecieron en número y ya no dependían sólo de parroquias y conventos sino también de las autoridades municipales y de los gremios de maestros. Sin embargo, todas coincidían en tener rasgos opuestos a los de los sistemas educativos modernos que conciben a la educación básica como un derecho y por ello es universal y obligatoria, gratuita y laica o, al menos, plural, ya que se trata de un servicio público a cargo del Estado. En el Antiguo Régimen, en cambio, la educación básica se distinguía por ser privilegio de una elite y, por consiguiente, de paga, por lo que era algo privado a cargo de la iglesia o el gremio -que era también una hermandad o cofradía-. Por esta razón, se daba por supuesto un fuerte contenido religioso. Un rasgo más era omnipresente: la organización que hoy llamamos multigrado, en la que un solo maestro atendía a un pequeño grupo de alumnos de edad y avance diferente.

Frente a este modelo de organización, los nuevos planteles educativos que surgieron en el siglo xv y prefiguran nuestra educación media superior, tenían varios maestros que se encargaban de la enseñanza de un número mayor de estudiantes organizados en varios grados, formados por chicos de edad y/o avance similar.

Este modelo fue desarrollado por primera vez en la población de Zwolle en los Países Bajos por Joan Cele, de los Hermanos de la Vida Común. En su escuela, los alumnos se repartían en clases homogéneas que se sucedian anualmente, de la octava a la primera, según un avance regular. Un examen permitía acceder a la siguiente clase. Este modelo educativo fue introducido en Francia en 1490 por el director del Colegio Montaigu de París, Jean Standonck, y pasó a conocerse como el modus parisiensis (Frijhoff, 1994: 1254; Gaulupeau, 1992: 28-32).

Ignacio de Loyola, fundador de la Compañía de Jesús, había sido alumno del Colegio Montaigu, cuya influencia es evidente en la organización de los liceos jesuitas que a partir de la segunda mitad del siglo XVI rivalizaron con las decadentes universidades para la formación de la elite social de los países católicos. En 1556, los jesuitas establecieron en Billom el primero de muchos colegios nuevos o liceos que marcarían el desarrollo de la educación en Francia y otros lugares.

Del siglo XIII al Xv, las universidades bastaban para formar una reducida elite del saber: teólogos, médicos y juristas, entre los que la Iglesia y el Estado escogían a la 
mayor parte de sus grandes servidores. Con los colegios, hijos del Renacimiento y de las reformas religiosas, es toda la elite social la que toma poco a poco el camino de la escuela para adquirir en ella una nueva cultura, humanista y cristiana, la del "hombre honesto". (Gaulupeau, 1992: 25)

En el mismo sentido, Jacques Minot apunta:

A pesar de algunos indicios alentadores, se anuncia el declinar de las universidades. Las facultades de artes se estacan y acaban por morir frente a la competencia de los nuevos colegios, en particular, los de los jesuitas, de espíritu mucho más moderno. (Minot, 1991: 28)

En el norte de Europa, la Reforma protestante, junto con otros factores, influyó para que el desarrollo de las instituciones educativas fuera mayor, pero en la dirección apuntada. El nuevo modelo fue introducido en 1538 por Johan Sturm en el gymnasium de Estrasburgo, que era una combinación de grammar school y college universitario; en 1540, Claude Baduel lo implantó en Nimes y ambos reconocen como inspirador a Philip Melanchthon, el llamado Praeceptor Germaniae.

El modelo del gymnasium -que adoptaron todas las instituciones educativas luteranas del Imperio Alemán, Escandinavia y el Báltico, y luego de Escocia y otros lugares- comprendía una grammar school organizada por grados complementada por una superestructura semi-universitaria donde catedráticos enseñaban elementos de filosofía y en ocasiones materias de las facultades superiores. Estos planteles -adscritos a una universidad o independientes- atendían mejor las necesidades educativas que las viejas instituciones, cuyo alumnado se redujo. Los estudiantes de la Facultad de Artes de la Universidad de París, por ejemplo, que en 1470 eran 2,200, pasaron a menos de 300 en 1620 (Frijhoff, 1992: 1254-1255).

La expansión limitada de la media superior: el modelo educativo dual

La necesidad de que toda persona supiera al menos leer y escribir hizo que la enseñanza elemental se definiera como obligatoria desde el siglo XIX en los países más avanzados y, también, tempranamente en otros menos desarrollados, cuyas leyes reflejaban aspiraciones ampliamente compartidas, aunque su cumplimiento estuviera lejano en la realidad. Tal fue el caso de México, donde la primaria se concebía 
ya como obligatoria en la Constitución de 1857, aunque llevó más de un siglo acercarse a que el precepto se cumpliera.

Hasta el siglo xvil se juzgaba normal que en una sociedad fuera minoritaria la población que supiera leer y escribir y que la mayoría fuera analfabeta. Prevalecía la idea de que leer era una habilidad innecesaria e incluso peligrosa para la mayoría de la población. Philippe Aries ha mostrado que cuando la escuela secundaria comenzó a extenderse, apareció también una postura que veía con malos ojos esa tendencia. A diferencia de algunos reformadores del siglo xvil que veían en la instrucción el único medio de moralizar a los indigentes y volverlos trabajadores útiles para los oficios, en el XvIII aparece la idea de que: "Debe negarse el acceso a la enseñanza secundaria a los hijos del pueblo [...], que la instrucción debe estar reservada a los ricos, porque si se extiende a los pobres los alejará de los trabajos manuales y hará de ellos unos fracasados [...] (1973: 346).

La Chalotais creía que había: "Demasiados maestros, demasiadas escuelas secundarias [...] incluso el pueblo quiere estudiar; los campesinos y los artesanos envían a sus hijos a las escuelas secundarias de los pueblos [...]". Y añadía que los estudios de mala calidad que cursan, "les han enseñado a desdeñar la profesión de su padre [...]". Además de sostener que las escuelas de latín y la secundaria deberían prohibirse a los campesinos, consideraba que también la educación elemental era negativa y criticaba a los Hermanos de las Escuelas Cristianas (a los que designaba con el mote burlesco popular de ignorantins) porque: "Enseñan a leer y escribir a personas que sólo deberían aprender a dibujar y a manejar el cepillo y la lima pero ya no quieren hacerlo" (Aries, 1973: 347).

Llama la atención que destacados pensadores de la Ilustración compartieran esas ideas. Voltaire, por ejemplo, felicitó a La Chalotais por las ideas anteriores y le escribió:

Le agradezco que proscriba el estudio a los campesinos. Yo, que me dedico al cultivo de la tierra, lo que busco es tener mano de obra y no clérigos tonsurados $[\ldots]$ conviene que el pueblo sea conducido y no que sea instruido [...], me parece esencial que haya indigentes ignorantes [... J. (Aries, 1973: 348)

Antes de la Revolución Industrial, de la Ilustración y la democracia moderna, era funcional una población con una minoría capaz de leer y escribir y una gran mayoría analfabeta dedicada a la agricultura, la 
ganadería y algunos oficios. La expansión de la educación primaria puede verse, en parte, como la aceptación de que una capacidad mínima de lectura era necesaria para todos, en sociedades en que la Revolución Industrial había transformado el trabajo al que debía dedicarse la mayor parte de la población, y las revoluciones políticas comenzaban a suponer la existencia de ciudadanos también mínimamente informados. Sólo las elites necesitaban conocimientos más complejos, por lo que la división entre personas con educación media y superior, frente a otras sólo con primaria, sustituyó a la anterior, entre letrados y analfabetas. Esto se refleja en que la expansión de los sistemas educativos durante el siglo XIX se caracterizó en general por la temprana separación de las trayectorias corta y larga de la escolaridad, en lo que se suele denominar un sistema educativo dual. Como escribe en 1801 uno de los más destacados pensadores conservadores de la primera mitad del siglo XIX, a quien se atribuye la introducción del término ideología, Destutt de Tracy:

Los hombres de la clase obrera necesitan tempranamente del trabajo de sus hijos, y ellos mismos necesitan adquirir tempranamente el hábito y la costumbre del trabajo penoso al que están destinados. Por ello no pueden perder demasiado tiempo en la escuela $[\ldots]$. Concluyamos, pues, que en todo Estado bien administrado $[\ldots]$ debe haber dos sistemas de enseñanza completos, que no tienen nada en común el uno con el otro. (En Gaulupeau, 1992: 68)

Frente al modelo educativo dual, los sistemas de tipo comprensivo se distinguen porque en ellos, en principio, todos los alumnos asisten a escuelas similares durante la educación secundaria, al menos en su parte básica, y en alguna medida también en la superior. Esta opción suponía una visión diferente, más igualitaria: el acceso a la educación posterior a la primaria no tiene por qué estar reservado a los hijos de una minoría. La idea de que la educación es un derecho universal debe abarcar la enseñanza media superior.

La primera concepción prevaleció en la mayor parte de los países hasta bien entrado el siglo xx y sólo algunos tomaron tempranamente la segunda dirección. Por ello hasta hace algunas décadas, los sistemas educativos de casi todos los países estaban estructurados con base en el supuesto implícito de que era natural y aceptable que sólo una minoría de alumnos tuviera buenos niveles de aprendizaje en la escuela primaria o elemental y accediera a niveles superiores, en tanto 
que el grueso del alumnado no lo conseguía y debía dejar la escuela al final de la primaria, para dedicarse a ocupaciones de tipo manual.

La excepción a esa tendencia la constituyó Estados Unidos de América que desde el siglo XIX adoptó un enfoque comprensivo para su educación secundaria. En Europa, la adopción de un modelo comprensivo se dio por vez primera hasta mediados del siglo xx en Suecia. El cambio del sistema educativo de ese país fue parte del proceso que llevó al estado de bienestar, fruto de un movimiento social iniciado desde fines del XIX. Hasta entonces, el sistema sueco tenía las dos redes diferenciadas tradicionales: la que atiende a una minoría de niños y jóvenes de clase media y alta y llega hasta la universidad, y la destinada a los hijos de las clases populares, que se reducía a una escuela elemental de baja calidad, después de la cual se entraba al mercado laboral, a veces con la limitada enseñanza de un oficio.

Una comisión del parlamento sueco creada en 1946 para definir cómo se debería organizar el sistema educativo llegó a la conclusión de adoptar un modelo comprensivo contra las ideas generalmente aceptadas a partir de estudios sobre el desarrollo de las habilidades de los chicos de 7 a 16 años que mostraron, entre otras cosas, que los medios utilizados para supuestamente detectar la aptitud académica de los estudiantes eran poco confiables y tenían un fuerte sesgo sociocultural; que muchos chicos así seleccionados fracasaban posteriormente en los estudios, y que no era cierto que los chicos con mayores aptitudes académicas tuvieran menos habilidades prácticas y viceversa (Husén, 1986: 156).

Poco a poco otros países han dado un enfoque comprensivo a sus sistemas educativos, al tiempo que han aumentado el lapso comprendido por la escolaridad obligatoria, llevándolo hasta los 15 años y en algunos casos hasta los 18. Así ocurrió primero en los demás países escandinavos, luego en países anglosajones no europeos y en el resto de Europa, en Asia oriental y, más recientemente, en Iberoamérica.

El cambio de las ideas dominantes refleja influencias de dos tipos de factores: por una parte, la creciente sensibilidad a los derechos humanos y a valores de igualdad, justicia, equidad y solidaridad; por otra, las necesidades que plantean a la educación las nuevas tendencias de la economía y, en particular, de los mercados laborales. 
Los cambios de las concepciones valorales y la extensión de la educación

Tradicionalmente se aceptaba como natural la desigualdad entre grupos sociales, como europeos e indígenas americanos, negros y blancos o mujeres y hombres, niños de familias pobres o acomodadas. Esas ideas dejan cada vez más el lugar a la aceptación, al menos teórica, del valor de la igualdad fundamental de todos los seres humanos, fundamento de los pactos internacionales como el que dio origen a la Organización de las Naciones Unidas. Este trascendental cambio se refleja en la evolución de la noción de educación básica en los documentos oficiales de la ONU y la UNESCO.

La Declaración Universal de Derechos Humanos de 1948 establece el derecho universal a la educación, pero limita a la elemental las nociones de gratuidad y obligatoriedad, en tanto que para la educación técnica y profesional usa la expresión habrá de ser generalizada, y para la educación superior indica que el acceso a los estudios superiores será igual para todos, en función de los méritos respectivos (ONU, 1948).

La Declaración Mundial sobre Educación para Todos, adoptada en Jomtien en 1990, comenzaba diciendo, en relación a la Declaración de 1948: "Hace más de cuarenta años, las naciones del mundo afirmaban [...] que toda persona tiene derecho a la educación". Luego añadía que pese a los esfuerzos realizados, todavía más de 100 millones de niños, de los cuales al menos 60 millones son niñas, no tienen acceso a la primaria y ofrece otros datos preocupantes sobre los adultos analfabetas y sobre quienes comienzan la primaria pero no la terminan (Commission Interinstitutions, 1990: 45).

En el Marco de Acción que sigue a la Declaración de Jomtien, se encuentra la siguiente precisión en cuanto a los objetivos específicos que los países deberían fijar para alcanzar durante la década de los años noventa:

- Universalización de la educación primaria o de cualquier otro nivel de educación más elevado que se considere "fundamental" de aquí al año 2000, y no sólo en lo que se refiere al acceso al ciclo de estudios, sino también a su terminación. (Commission Interinstitutions, 1990: 57)

En el año 2000, el Foro de Dakar dio continuidad a la política de Educación Para Todos lanzada en Jomtien. Uno de los documentos pre- 
paratorios da un paso más en la dirección de extender la noción de educación básica a la secundaria.

El concepto de educación básica no es fijo o del todo claro y la mayoría de los países han decidido limitar la noción de "básica" a la educación primaria [... ]. En un número creciente de países, sin embargo, "básico" ahora comprende la secundaria básica y en otros se extiende hasta la secundaria superior completa. (EFA Forum, 2000: 2)

Esos cambios en las concepciones de la UNESCO y muchos países se ven apoyados por los avances de la investigación que muestran la falta de sustento de la antigua creencia de que habría diferencias insalvables de capacidades entre ciertos grupos y, en particular, que sólo una pequeña parte de las personas tendría capacidad para hacer con éxito estudios superiores o, en general, para adquirir competencias complejas.

La opinión de que la inteligencia está determinada genéticamente no ha desaparecido por completo; todavía a fines del siglo xx era sostenida por científicos importantes, como muestra la publicación de The Bell Curve (Herrnstein y Murray, 1994). Varias publicaciones que reaccionaron ante los planteamientos de esa obra (Jencks y Phillips, 1998; Neisser, 1998) mostraron que la opinión de otros científicos reconocidos era diferente. Nisbett hace el siguiente balance de la situación actual:

A fines del siglo xx muchos de los expertos sobre el tema, si no la mayor parte de ellos, creían que la inteligencia y el talento académico estaban sustancialmente bajo control genético [...]. Esos expertos eran muy escépticos en cuanto al posible éxito de cualquier esfuerzo por mejorar la inteligencia y no se sorprendían cuando intervenciones como las de la educación temprana no conseguían tener efectos duraderos. Dudaban mucho de que las personas pudieran volverse más inteligentes como resultado de mejoras en la educación o de cambios en la sociedad. Sin embargo, los resultados de las recientes investigaciones en psicología, genética y neurociencia, junto con los actuales estudios sobre la eficacia de las intervenciones educativas, han puesto de cabeza la postura hereditaria sobre la inteligencia. Ahora se considera claro que la inteligencia es altamente modificable por el medio. Sin educación formal una persona simplemente no será muy brillante, sea que la inteligencia se mida con pruebas de Cociente Intelectual (IQ) o de cualquier otra forma. Y que el IQ de cualquier persona, así como sus resultados académicos y su éxito 
ocupacional sean altos o bajos depende en buena medida de factores ambientales que no tienen nada que ver con sus genes. (Nisbett, 2009: 1-2)

La inteligencia puede variar y varía gracias a la mayor o menor exposición de los sujetos a la educación formal. Hay intervenciones que tienen impacto considerable y las de resultados más notables y duraderos se caracterizan por hacerse en los primeros años de vida de los niños, en formas intensivas y costosas, pero que inciden de manera profunda en su desarrollo. Hay base suficiente para una opinión razonablemente optimista en cuanto a las posibilidades de la escuela. No se trata de adoptar una postura ingenua, pero sí de escapar al determinismo que da un peso excesivo a los factores extraescolares, genéticos o del medio social y familiar, así como al pesimismo derivado de ello. La visión que expresa Nisbett apoya la idea de que es posible que un sistema educativo de enfoque comprensivo lleve a todos los alumnos a alcanzar niveles de aprendizaje que antes se pensaba sólo podían lograr unos cuantos.

\section{Los nuevos mercados laborales y la expansión de la educación}

El segundo tipo de razones, cuya influencia posiblemente sea más importante para explicar la extensión de la escolaridad hasta los 18 años, tiene que ver con las demandas que se presentan en los nuevos mercados laborales que se deben, a su vez, de las necesidades de las economías avanzadas.

Estudios norteamericanos muestran que en la segunda mitad del siglo xx la proporción de puestos de trabajo de tipo manual disminuyó, en tanto que los puestos gerenciales, administrativos y de servicios aumentaron.

El título de otra obra en este sentido es elocuente: La nueva división del trabajo: cómo están creando el siguiente mercado laboral las computadoras (Levy y Murnane, 2004). Un estudio anterior muestra que en las últimas décadas del siglo xx la demanda de habilidades de tipo manual (rutinario o no) y las de tipo cognitivo-rutinario, disminuyó entre 3 y 8 puntos, al tiempo que aumentaba entre 8 y 14 puntos la demanda de competencias complejas de comunicación y pensamiento experto (Autor, Levy y Murnane, 2003).

La consecuencia para los sistemas educativos es clara: cada vez será más necesario que, al fin de su paso por la escuela, los jóvenes 
tengan conocimientos y habilidades que no se desarrollan durante los años de la primaria ni los de la secundaria básica.

La creciente necesidad de personas con competencias complejas en los nuevos mercados laborales junto con la convicción de que la mayor parte de los alumnos puede alcanzar esas competencias si las escuelas funcionan bien y la atención a los niños -en especial los de medio desfavorable - comienza a temprana edad y se prolonga lo suficiente, constituye una combinación poderosa que impulsa la tendencia a extender la escolaridad obligatoria hasta el fin de la secundaria superior, hacia los 18 años de edad.

Debe añadirse que conseguir que todas las personas tengan al menos educación media superior es necesario no sólo para tener economías competitivas, sino también para que puedan funcionar democracias maduras y sociedades cohesionadas. Y si la prosperidad económica es importante, la democracia y la cohesión lo son tanto o más, lo que implica la necesidad de que todo joven acceda a niveles educativos medios o superiores, y que gracias a ellos desarrolle las competencias para la vida en tales sociedades.

Hacia el futuro: la difícil generalización de la media superior

Hoy se considera que para que una persona pueda tener una vida satisfactoria no sólo en lo económico, sino también en lo político y lo cultural, la enseñanza primaria y la secundaria básica no bastan, sino que son indispensables 12 años de escolaridad. Por otra parte, no es fácil conseguir que todos los jóvenes lleguen a la secundaria superior, la terminen y lo hagan con un dominio suficiente de las competencias complejas necesarias para enfrentar los retos de las sociedades contemporáneas. De hecho ningún país lo ha conseguido del todo y algunos de los más desarrollados enfrentan dificultades considerables para ello.

No suele haber datos sobre el acceso a la educación media superior de mediados del siglo XIX a mediados del XX. Hay que recordar, sin embargo, que los sistemas educativos duales hacían que la elite que llegaba a la universidad se separara tempranamente de la masa que iría a desempeñar trabajos manuales, dejando la escuela al terminar la primaria o, a lo más, la secundaria básica. Los que accedían a la media superior, por su parte, llegaban casi todos a la universidad. Por ello es posible usar las cifras de acceso a la educación superior como indica- 
dores aproximados del acceso a la media superior en periodos antiguos en los que no se cuenta con otros datos.

Tabla 1. Tasas de escolarización en la educación superior en algunos países, como porcentaje del grupo de 20 a 24 años de edad.

\begin{tabular}{lcccccccc}
\hline \multicolumn{1}{c}{ País } & 1870 & 1880 & 1890 & 1900 & 1910 & 1920 & 1930 & 1985 \\
\hline Alemania & 0.6 & 0.6 & 0.6 & 1.0 & 1.2 & 1.9 & 2.6 & 29.4 \\
\hline Francia & 0.5 & 0.6 & 0.9 & 1.2 & 1.7 & 2.0 & 2.9 & 30.0 \\
\hline Reino Unido & 0.4 & 0.6 & 0.7 & 0.8 & 1.3 & 1.6 & 1.9 & 22.3 \\
\hline Estados Unidos & 2.3 & 3.4 & 3.5 & 5.0 & 5.6 & 9.0 & 11.2 & 64.4 \\
\hline
\end{tabular}

Fuente: Charle y Verger, 1994, Tabla 2, p. 122.

Las cifras de los países europeos muestran lo reducido que era el acceso a la educación superior -y, por inferencia, a la media superioren las últimas décadas del siglo XIX y las primeras del XX. El último renglón muestra el caso de Estados Unidos que, desde la segunda mitad del XIX, mucho antes que los demás países, optó por una educación de tipo comprensivo basada en la idea de que todos los niños, y no sólo los hijos de la elite, pueden aspirar a realizar estudios superiores.

La última columna, por su parte, muestra cómo a mediados de la década de 1980 la tendencia a la universalización de la educación superior -y sin duda a la expansión aún mayor de la media superior- habían avanzado ya en forma importante en países altamente industrializados de Europa, pero también que Estados Unidos todavía mostraba cifras muy superiores a ellos.

La Tabla No. 2 muestra datos de 2007 de la población de 25 a 64 años de edad con al menos media superior. Al desagregarse por grupos de edad, los datos revelan la forma en que se extendió ese nivel educativo. Los encabezados de columnas muestran que quienes en 2007 tenían de 55 a 64 años de edad nacieron entre 1943 y 1952, y debieron terminar la media superior entre 1961 y 1970. Los grupos de 45 a 54,35 a 44 y 25 a 34 años, por su parte, permiten apreciar lo que pasó en los años 70, 80 y 90 del siglo pasado. 
Tabla 2. Porcentaje de la población que tiene al menos educación media superior, por grupos de edad de 25 a 64 años (2007).

\begin{tabular}{|c|c|c|c|c|}
\hline \multirow{4}{*}{ Países } & \multicolumn{4}{|c|}{ Grupos de edad, década de nacimiento y fin de EMS } \\
\hline & $55-64^{*}$ & $45-54^{*}$ & $35-44^{*}$ & $25-34^{*}$ \\
\hline & $1943-1952 * *$ & $1953-1962 * *$ & $1963-1972 * *$ & $1973-1982^{* *}$ \\
\hline & $1961-1970 * * *$ & $1971-1980 * * *$ & $1981-1990 * * *$ & $1991-2000 * * *$ \\
\hline México & 18 & 29 & 37 & 39 \\
\hline Brasil & 22 & 31 & 37 & 47 \\
\hline Chile & 32 & 44 & 52 & 64 \\
\hline Portugal & 13 & 20 & 27 & 44 \\
\hline España & 28 & 44 & 56 & 65 \\
\hline Italia & 34 & 48 & 56 & 68 \\
\hline Grecia & 37 & 53 & 67 & 75 \\
\hline Francia & 53 & 63 & 74 & 83 \\
\hline R. Unido & 61 & 66 & 69 & 75 \\
\hline Finlandia & 65 & 81 & 87 & 90 \\
\hline Suecia & 74 & 83 & 90 & 91 \\
\hline Alemania & 81 & 85 & 86 & 85 \\
\hline Polonia & 74 & 86 & 90 & 92 \\
\hline Rusia & 71 & 89 & 94 & 91 \\
\hline Estados Unidos & 87 & 89 & 88 & 87 \\
\hline Corea del Sur & 39 & 65 & 92 & 97 \\
\hline
\end{tabular}

Notas: ${ }^{*}$ Edad ${ }^{* *}$ Fecha de nacimiento ${ }^{* * *}$ Fecha de fin teórico de media superior. Fuente: INES (2009). Education at a Glance, 2009. Tabla A1.2a, p. 38.

Los tres primeros países son latinoamericanos y tienen los porcentajes más bajos de personas con al menos educación media superior, tanto en el grupo de mayor edad como entre los más jóvenes. Ya en la década de 1960, Brasil y Chile tenían cifras más altas que México; en los tres países la población más joven, que llegó a la media superior en la década de 1990, lo hizo en proporciones que duplicaban las de sus antepasados, pero ese avance similar se traduce en distancias crecientes tres décadas más tarde.

La tabla muestra luego cifras de países del área mediterránea, del centro y norte de Europa, la región escandinava y los antiguos países socialistas, que permiten apreciar diferentes situaciones hacia $1960 \mathrm{y}$ diferentes evoluciones en las décadas siguientes. Al final de la tabla, Estados Unidos, que tenía las cifras más altas en la década de 1960, treinta años más tarde no muestra crecimiento alguno (87\%), por de- 
bajo de varios de los países que se presentan. En fuerte contraste con Estados Unidos y todos los demás países, Corea del Sur en los años 60 del siglo xx tenía una población con al menos media superior de 39\%, que sólo superaba a la de los tres países latinoamericanos y cuatro mediterráneos, mientras que a fines del siglo alcanzó la cifra más alta de todos: $97 \%$.

La Tabla 3, que incluye sólo a países de la Unión Europea, complementa la información de la anterior para años más recientes, con dos tipos de datos: la proporción de personas que seguía en el sistema educativo a la edad de 18 a 24 años; y tasas netas de escolaridad de 15 a 18 años. Téngase en cuenta que quienes tenían de 18 a 24 años de edad en 2007 nacieron entre 1983 y 1989 y debieron cursar la secundaria superior entre 2001 y 2007.

Tabla 3. Tasas netas de escolaridad de 15 a 18 años de edad 2006-2007.

\begin{tabular}{lcccc}
\hline \multirow{2}{*}{ Países } & \multicolumn{4}{c}{ Tasas netas de escolaridad, curso 2006-2007 } \\
\cline { 2 - 5 } & 15 años & 16 años & 17 años & 18 años \\
\hline Portugal & 99.7 & 90.8 & 80.0 & 64.8 \\
\hline España & 99.2 & 93.4 & 83.1 & 70.0 \\
\hline Italia & 93.5 & 89.2 & 83.4 & 78.1 \\
\hline Grecia & 92.1 & 89.5 & 84.9 & 65.9 \\
\hline Francia & 98.3 & 93.9 & 89.5 & 76.6 \\
\hline Finlandia & 99.3 & 95.9 & 95.1 & 93.8 \\
\hline Suecia & 95.5 & 99.0 & 97.6 & 94.8 \\
\hline Polonia & 98.1 & 97.3 & 95.4 & 93.9 \\
\hline Alemania & 98.2 & 96.0 & 92.3 & 84.8 \\
\hline
\end{tabular}

Fuente: IE (2010a). Informe 2009: Objetivos educativos y puntos de referencia 2010, pp. 58 y 62 .

En todos los países, las tasas netas de asistencia a la escuela a los 15 años de edad son superiores a 90\%; en Finlandia, España y Portugal, rebasan 99\%. Luego, las cifras bajan ligeramente en Suecia, Polonia y Finlandia en los jóvenes de 18 años que tienen tasas netas de asistencia cercanas a 95\%; y más rápido en Grecia y Portugal, con asistencia neta a los 18 años de alrededor de 65\%; España alcanza $70 \%$; Francia e Italia no llegan a $80 \%$. 
Todavía a fines de la primera década del siglo Xxi ningún país ha conseguido que todos sus jóvenes terminen la secundaria superior. En varios casos la proporción que no lo consigue representa $20 \%$ o incluso más de $30 \%$ de cada cohorte.

En 1985, el presidente de Francia, Francois Miterrand, estableció la meta de que en el año 2000 100\% de los jóvenes prosiguiera estudios hasta los 18 años de edad y que $80 \%$ lo hiciera en los programas que preparan para la universidad, de manera que una proporción cercana a esa obtuviera el baccalaureat. Las cifras recién analizadas muestran que esa meta no ha podido alcanzarse todavía. De hecho, después de un rápido avance entre 1985 y 1995, las cifras no han mejorado (cfr. Beaud, 2003; Forestier y Thélot, 2007).

Un indicador de la Unión Europea da la misma información pero en sentido negativo, es decir, el abandono escolar temprano definido como el porcentaje de jóvenes de 18 a 24 años de edad que consiguió a lo más terminar la secundaria básica y que no sigue estudiando.

La importancia que conceden a este indicador las políticas educativas de todos los países de la Unión Europea se refleja en el hecho de que uno de los puntos de referencia que estableció la Estrategia de Lisboa, adoptada por el Consejo Europeo en 2000 como meta a alcanzar en 2010 fue, precisamente, que en ningún caso dicho abandono temprano superara la cifra de 10\% (Instituto de Evaluación, 2010b: 15).

En España se considera que alcanzar esa meta constituye uno de los retos más importantes del sistema educativo. En 2007, el porcentaje de jóvenes de esa edad que no seguía estudios después de terminar la secundaria básica era 31\% y en 2008 subió a 31.9\%, más del doble de la cifra de la Unión Europea (15.2 y 14.9\%, respectivamente), todavía lejos, a su vez, de la meta mencionada (Instituto de Evaluación, 2009: 25 y 59).

La Tabla 4 muestra que en 2008 sólo Polonia y Finlandia tienen cifras menores a $10 \%$, en tanto que España y Portugal todavía presentan más de $30 \%$ e Italia casi $20 \%$. 
Tabla 4. Porcentaje de población de 18 a 24 años que ha completado como máximo la secundaria básica y sigue o no estudiando. Unión Europea. 2008.

\begin{tabular}{lcccc}
\hline \multirow{2}{*}{ Países } & \multicolumn{3}{c}{ No sigue estudiando } & \multirow{2}{*}{ Sigue estudiando } \\
\cline { 2 - 4 } & Ambos sexos & Mujeres & Hombres & \\
\hline Alemania & 11.8 & 11.2 & 12.4 & 88.2 \\
\hline España & 31.9 & 25.7 & 38.0 & 68.1 \\
\hline Finlandia & 9.8 & 7.7 & 12.1 & 90.2 \\
\hline Francia & 11.8 & 9.8 & 13.8 & 88.2 \\
\hline Grecia & 14.8 & 10.9 & 18.5 & 85.2 \\
\hline Hungría & 11.7 & 10.9 & 12.5 & 88.3 \\
\hline Irlanda & 11.3 & 8.0 & 14.6 & 88.7 \\
\hline Italia & 19.7 & 16.7 & 22.6 & 80.3 \\
\hline Polonia & 5.0 & 3.9 & 6.1 & 84.0 \\
\hline Portugal & 35.4 & 28.6 & 41.9 & 83.0 \\
\hline Reino Unido & 17.0 & 15.6 & 18.3 & 88.9 \\
\hline Suecia & 11.1 & 9.9 & 12.3 & 16.9 \\
\hline U. Europea & 14.9 & 12.9 & & 85.1 \\
\hline
\end{tabular}

Fuente: IE (2010a). Informe 2009: Objetivos educativos y puntos de referencia 2010. Tabla 2.1, p. 58 .

A diferencia de otras metas de la Estrategia de Lisboa, en abandono escolar temprano no se avanzó bastante hacia la meta adoptada en 2000. Esto hizo que el Consejo de Ministros de la Unión Europea de mayo de 2009 mantuviera la cifra de 10\% de abandono escolar como meta a alcanzar en la década siguiente, esto es, en el 2020 (Instituto de Evaluación, 2010b: 17)

\section{CONCLUSIÓN}

El reto de la universalización de la media superior para México

Algunos países de la Unión Europea consideran obligatoria la asistencia a la escuela hasta los 18 años, pero en otros la obligatoriedad llega hasta edades menores, como en España, en donde llega a los 16 años. 
Lo que tienen en común dichos países es que se han propuesto que la gran mayoría de sus jóvenes siga estudiando al menos hasta el fin de la media superior, hacia los 18 años, y que han definido políticas precisas para conseguirlo, independientemente de que la meta se defina como obligatoria o no.

En México se ha comenzado por poner en la ley una obligación, aunque se sepa que no será posible cumplirla en cierto tiempo, como pasa con la obligatoriedad de la secundaria, fijada legalmente en 1993 y aún por cumplir. Lo mismo pasó con la obligatoriedad de los tres grados de educación preescolar, adoptada en 2002 con un horizonte al 2008 ya rebasado, y otro tanto pasará sin duda con la obligatoriedad de la media superior, que en 2012 se incorporó a la Constitución, estableciendo el año 2021 como fecha para su pleno cumplimiento.

Para alcanzar propósitos tan ambiciosos no basta modificar la ley; son necesarias muchas condiciones más. Cuando recientemente en Argentina se decidió hacer obligatorio asistir a la escuela hasta los 18 años, el ministro de educación apuntaba que tomar en serio ese reto implicaba reconocer sus implicaciones no sólo para el sistema educativo sino para la sociedad toda, ya que los medios necesarios para hacerlo realidad no se limitan a tener lugares disponibles para atender la demanda, sino muchas otras cosas para que la escuela sea realmente accesible a todos los jóvenes, y también para que sea relevante para ellos.

En México todavía alrededor de 15\% de los jóvenes no consigue terminar la secundaria básica y la mitad del total no termina la media superior, por lo que el reto es mayor. Para apreciar sus dimensiones es necesario no limitarse a la consideración de los aspectos cuantitativos, sino incluir en el análisis sus diversas y complejas aristas cualitativas. Como se acaba de decir, el reto no se limita a que el número de lugares teóricamente disponibles en media superior sea igual o mayor al de los jóvenes que terminan la secundaria, sino que se necesitan otras cosas para que la escuela sea realmente accesible.

Es necesario que los lugares disponibles estén razonablemente cercanos al domicilio de los demandantes, pero también que todos terminen el nivel anterior y lo hagan a una edad y con un nivel de aprendizaje que les permitan seguir adelante con probabilidades de éxito, lo cual implica que todos los niños comiencen la enseñanza básica a la edad apropiada y que recorran sus etapas en el tiempo estipulado y con niveles de aprendizaje aceptables, ya que el abandono prematuro de la escuela tiene como antecedentes claros el bajo rendimiento y la 
extraedad; esta última debida a su vez al ingreso tardío o a la reprobación previa de uno o más grados. Este fenómeno, estudiado hace ya más de 30 años en México por Carlos Muñoz Izquierdo (1979), se encuentra invariablemente en los sistemas educativos en los que el abandono temprano es un problema importante.

A los hallazgos anteriores se añade lo que se sabe en México, en el sentido de que la necesidad económica no es el factor principal que explica la deserción de los jóvenes en secundaria y educación media superior. Mucho más importante es la falta de interés por una escuela que se encuentra poco atractiva e irrelevante. No deja de ser importante, desde luego, que la familia no requiera que los jóvenes trabajen para contribuir al sostenimiento del hogar, e incluso que los puedan apoyar económicamente mientras son improductivos en términos económicos, pero es aún más importante que los jóvenes mismos vean a la escuela como algo interesante, más atractivo que los trabajos a los que pueden tener acceso, ya que a los 15 años o más no basta que los padres quieran que sus hijos vayan a la escuela, sino que ellos también deben quererlo.

A propósito del fracaso del sistema educativo francés para alcanzar la meta de que en el año 2000 todos los jóvenes estuvieran en la escuela hasta los 18 años y $80 \%$ en el baccalaureat, un ministro de educación de ese país se preguntaba qué hace falta para convencerse de que ciertos elementos de la llamada alta cultura no interesan a la mayoría de los muchachos, después de que muchos de ellos han reprobado dos y tres veces por no leer a Balzac.

Por otra parte, la investigación señala que el éxito en la educación media depende en gran medida de lo que pase en el hogar, en el preescolar y en los primeros años de la primaria.

Según Hart y Risley (1995 y 1999), desde los primeros meses de vida se marca la diferencia entre hijos de padres con educación superior que oyen en promedio 2,000 palabras por hora, en contraste con hijos de clase trabajadora a los que se dirigen 1,300 palabras y, sobre todo, con los niños más pobres, que sólo escuchan en promedio 600 palabras por hora. Además, los padres del primer grupo hacen seis comentarios elogiosos a sus hijos por un regaño; los padres de clase trabajadora hacen sólo dos comentarios elogiosos por cada regaño; los niños más pobres reciben dos regaños por cada comentario elogioso. Las diferencias se acumulan: a los tres años de edad, en los extremos socioeconómicos unos niños han recibido 500,000 elogios y 80,000 re-

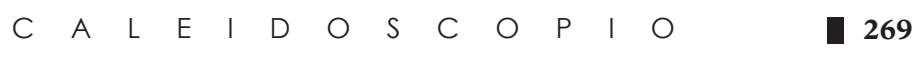


gaños; otros 75,000 elogios y 200,000 regaños. Unos han oído 30 millones de palabras y otros sólo 10 millones (Nisbett, 2009: 86, 111-112, 116).

Los niños aprenden a leer durante los primeros años del trayecto escolar y en general se espera que al fin del tercer grado de la primaria todos lo hayan conseguido; a partir de ese momento la lectura ya no debería ser un problema ni un objetivo a alcanzar, sino una herramienta para aprender otras cosas. Es la crucial transición de "aprender a leer" a "leer para aprender" (from learning to read to reading to learn). Al comenzar el cuarto grado de la primaria, sin embargo, todavía algunos alumnos tienen dificultades para leer: los que no han conseguido hacer a tiempo la transición mencionada. La proporción es especialmente grande en sistemas educativos con altas cifras de repetidores.

Después de seguir la trayectoria de alumnos de los seis a los 15 años, un trabajo canadiense concluye que la mayor parte de los que no consigue hacer exitosamente dicha transición entre los ocho y nueve años de edad avanza poco a partir de ese momento, hasta los 15. El trabajo muestra también que los niños que repiten el primer grado o el segundo tienen mucho menos probabilidades de hacer una transición exitosa entre los ocho y los nueve años, y que:

\footnotetext{
$75 \%$ de los estudiantes que tienen problemas con la lectura al final del tercero de primaria siguen teniéndolas en la educación media superior. Además, los que no consiguen hacer la transición de "aprender a leer" a "leer para aprender" tienen más probabilidades de presentar más tarde problemas de conducta, de manifestar falta de interés por la escuela y de abandonar la escuela prematuramente. (Beswick y Willms, 2008: 6)
}

Esos datos refuerzan la convicción de que, si se quiere que los jóvenes terminen con éxito y a tiempo la secundaria y sigan en la educación media superior, hay que mejorar los niveles educativos previos, pero también reorientar profundamente la media superior para que se vuelva una opción interesante para los jóvenes, que compita con el atractivo del dinero fácil de la delincuencia y sea relevante para quienes despiertan a la vida, están afirmando su identidad sexual, aprendiendo a respetar a los demás, preparándose para formar una familia y sostenerla, sin saber cómo mejorar una democracia muy imperfecta, confundidos ante las proclamas de credos viejos y nuevos poco auténticos, con una gama creciente de productos de consumo y sin elementos para orientarse entre ofertas culturales de muy distinto valor. 
Una reciente revisión de la investigación señala que hay cada vez más evidencia de que las curvas que grafican la evolución del aprendizaje de los estudiantes se vuelven planas durante la educación media, cuando muchos jóvenes muestran una fuerte disminución de su interés por la educación y menor aprendizaje. Después del fin de la escolaridad obligatoria, las curvas vuelven a mostrar una tendencia ascendente, reflejando tal vez el hecho de que los alumnos no interesados (disengaged) ya han dejado la escuela. Según este trabajo, los indicadores de interés decreciente se refieren a conductas más o menos preocupantes que van de aburrimiento y pasividad a delincuencia y autodestrucción. El trabajo también comenta un cambio interesante de los estudios sobre los adolescentes que antes centraban la atención casi exclusivamente en aspectos negativos y ahora se interesan también por capacidades de los jóvenes, en especial su creciente potencial cognitivo (Russell, 2010: 233-234).

Deben tenerse en cuenta las peculiaridades de los jóvenes destinatarios de la enseñanza media superior y su heterogeneidad. La investigación mexicana sobre juventud forma ya un cuerpo importante de trabajos (cfr. por ejemplo Pérez Islas, 2007) y su consulta es obligada para educadores muchas veces perplejos ante manifestaciones de subgrupos y subculturas que resultan extrañas a los mayores, educados al estilo tradicional.

Cuando llegaba a primaria sólo 30\% de los mexicanos, a principios del siglo XX, se trataba de niños urbanos que tenían condiciones favorables de salud, nutrición y otras. Al aumentar la cobertura llegaron a la escuela los niños de medio popular urbano, luego los de medio rural de mejores condiciones, después los niños campesinos más pobres y al final los de los grupos indígenas más marginados. Algo similar ocurre ahora en los siguientes niveles, con claras implicaciones para dar buena formación a un alumnado numeroso formado por jóvenes que, en proporción creciente, tendrán características distintas y aun opuestas a las que distinguían a los escasos alumnos de la media superior de 1950. El alumnado de educación media superior del siglo XXI estará formado cada vez más por jóvenes en pleno periodo de desfase entre su madurez biológica y psicológica que muchas veces deben combinar trabajo y estudio, con una perspectiva de su futuro plagada de signos de interrogación, desencantados de la vida política y las instituciones y fácil presa de manipulaciones ideológicas.

Las nuevas generaciones pueden ser más altas y fuertes y las TICS muestran que tienen gran capacidad de aprendizaje y más informa-

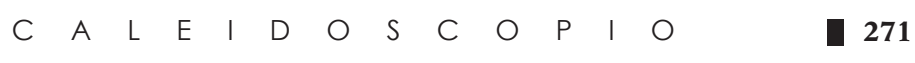


ción sobre el mundo que sus antecesoras. Los jóvenes de hoy no son peores que los de antaño; son distintos, y darles a todos buena educación media superior es un reto monumental, pero encararlo es indispensable si deseamos que México enfrente con éxito el triple reto de buscar la prosperidad económica, la democracia política y la integración cultural en forma abierta al mundo. Para ello hace falta mucha investigación sobre ese tipo educativo tan importante y tan descuidado.

\section{REFERENCIAS}

Aries, Ph. (1970). L'enfant et la vie familiale sous l'ancien régime. Paris: Seuil. Autor, D., Levy F. y Murnane R. J. (2003). The Skill Content of Recent Technological Change: An Empirical Exploration. The Quarterly Journal of Economics, 118 (4), pp. 1279-1333.

Beaud, S. (2003). 80\% au bac... et après? Paris: La Découverte.

Beswick, J. F. y Willms, D. J. (2008). The Critical Transition from “Learningto-Read" to "Reading-to-Learn". Series Successful Transitions: Findings from the National Longitudinal Survey of Children and Youth. Gatineau, Quebec. Human Resources and Social Development Canada Publications Center.

Charle, Ch. y Verger, J. (1994). Histoire des Universités. Paris: Presses Universitarires de France.

Chaunu, P. (1982). Historia y población. Un futuro sin porvenir. México: Fondo de Cultura Económica.

Cobban, A. B. (1994). Universities: 1100-1500. En Clark, B. R. y Neave, G. R. (Eds.). The Encyclopedia of Higher Education (1245-1251). OxfordNew York: Pergamon Press.

Collins, R. (1990). Cuatro tradiciones sociológicas. México: UAM.

Commission Interinstitutions (1990). Conférence mondiale sur l'éducation por tous: Répondre aux besoins éducatifs fondamentaux. New York: UNICEF.

Delors, J. (Coord.). (1996). La educación encierra un tesoro. UNESCO.

EFA Forum (2000). Briefing Papers. Contributed by UNESCO, pp. 1-8. Consultado en htpp://cyberschoolbus.un.org/briefing/education/ education.pdf.

Forestiere, Ch., Thélot, C. y Émin, J. C. (2007). Que vaut l'enseignement en France? Les conclusiones du Haut Conseil de l'évaluation de l'école. Paris: Stock. 
Firjhoff, W. (1994). Universities: 1500-1900. En Clark, B. R. y Neave, G. R. (Eds.). The Encyclopedia of Higher Education (1251-1259). OxfordNew York: Pergamon Press.

Gaulupeau, Y. (1992). La France a l'école. París: Gallimard.

Hart, B. y Risley, T. R. (1995). Meaningful Differences in the Everyday Experience of Young American Children. Baltimore: Paul H. Brookes Publishing Co.

Hart, B. y Risley, T. R. (1999). The Social Word of Children Learning to Talk. Baltimore: Paul H. Brookes Publishing Co.

Herrnstein, R. J. y Murray Ch. (1994). The Bell Curve. Intelligence and Class Structure in American Life. New York: The Free Press.

Husén, T. (1986). Why did Sweden Go Comprehensive? Oxford Review of Education. 12 (2), pp. 153-163.

Instituto de Evaluación (2009). Informe 2008: Objetivos Educativos y Puntos de Referencia 2010. Madrid: Ministerio de Educación.

Instituto de Evaluación (2010a). Sistema estatal de indicadores de la educación. Edición 2010. Madrid: Ministerio de Educación.

Instituto de Evaluación (2010b). Informe 2009: Objetivos Educativos y Puntos de Referencia 2010. Madrid: Ministerio de Educación.

INES (2009). Education at a Glance 2009. OECD Indicators. París: OECD.

Jencks, Ch. y Phillips, M. (Eds.). (1998). The Black-White Test Score Gap. Washington: Brookings Institution Press.

Johannesson, K. (1994). Quintilian and Education. En Husén, T. y Postlethwaithe, N. (Eds.). The International Encyclopedia of Education (48874890). Oxford-New York: Pergamon Press.

Levy, F. y Murnane, R. J. (2004). The New Division of Labor. How Computers are Creating the Next Job Market. Princeton: Princeton University Press.

Minot, J. (1991). Histoire des universités francaises. París: Presses Universitaires de France.

Muñoz Izquierdo, C. (1979). El síndrome del atraso escolar. Revista Latinoamericana de Estudios Educativos. IX (3), pp. 1-60.

Neisser, U. (Ed.) (1998). The Rising Curve. Long-Term Gains in IQ and Related Measures. Washington: American Psychological Association.

Nisbett, R. E. (2009). Intelligence and How to Get It. Why Schools and Cultures Count. New York: W. W. Norton and Co.

Organización de las Naciones Unidas (1948). Declaración Universal de los Derechos Humanos. Consultada en www.un.org.

Pérez Islas, J. A. (2008). Juventud: un concepto en disputa. En Pérez Islas, J. A., Valdez González, M. y Suárez Zozaya, M. H. (Coords.). 
Teorías sobre la juventud. Las miradas de los clásicos (9-33). México: UNAM, CIIJ, y Miguel Ángel Porrúa.

Perkin, H. (1997). History of Universities. En Goodchild, L. F. y Weschsler, H. S. (Eds.). The History of Higher Education (3-32). Needham Heights: Simon \& Schuster.

Russell, V. J. (2010). Perspectives on Schooling in the Middle Years. En Peterson, P., Baker, E. y McGaw, B. (Eds.). The International Encyclopedia of Education, $3^{\text {rd }} \mathrm{Ed}$. Vol. 2, 233-241. Oxford: Elsevier. 